\title{
When "SOP” Fails: Disseminating Risk Assessment in Aviation" Case Studies and Analysis
}

\author{
Ryan E. Quinn²
}

\author{
Saint Louis University
}

\begin{abstract}
In the early 1990s, a regional jet taking off from LaGuardia airport with ice and snow on the wings crashed into a nearby bay and killed 27 passengers and crew. The accident of USAir Flight 405 is studied critically in this review as a result of incomplete identification and dissemination of the risks involved in operations under icing conditions. The improper system risk dissemination and mitigation led the crew of USAir 405 to believe they were in a condition for a safe takeoff. In the larger context outside of this accident, unidentified hazards resulting from poor communication and company dissemination are still an everyday threat. I argue that this disconnect is a causal factor in Normalization of Deviance. Contemporary examples of safety incidents are used to support this argument and introduce possible new areas for monitoring and research. The author argues that companies should employ techniques to open new policies up for testing and feedback before being implemented as policy or standard operating procedure.
\end{abstract}

\section{Accident Narrative}

On the night of March 22nd, 1992, a fifty-passenger twin engine regional jet known as a Fokker F28-4000 lined up on runway 13 at LaGuardia Airport in New York City. With the Captain advancing the thrust levers, USAir 405 accelerated down the runway and reached one hundred thirteen knots. Upon "Vee R" being called out by the First Officer, the nose was raised to thirteen degrees pitch up under the Captain's command and three seconds later the Cockpit Voice Recorder (CVR) registered the sound of a stick shaker ${ }^{4}$ activation. Approximately three quarters down the runway the left wing began to scrape on the ground, and the aircraft rolled to the left, destroying the runway's approach slope lights and a water pumphouse. Four seconds from the initial rotation, the Fokker, now torn to shreds, laid inverted in the 34-degree Flushing Bay just a few feet off of airport property. A fire erupted and burned, mostly on top of the water, for 30 minutes before fire services were able to put it out. By the next morning, twenty seven of the fifty-one people onboard had lost their lives (Kleinfield, 1992; National Transportation Safety Board [NTSB], 1993). An investigation completed by the National Transportation Safety Board found that the sound of the stick shaker system was continuous

\footnotetext{
${ }^{1}$ This work has not been previously published and is not currently under consideration for publication elsewhere.

2 Email: quinnr@slu.edu. 421 Hanover St., Apt 31, Boston, MA, USA, 02113

3 "Vee R", as it is transcribed from the voice recorder, refers to $V_{R}$, the velocity at which the pilot pulls back on the control yoke.

${ }^{4}$ Stick shakers alert the pilot of an impending aerodynamic stall.
} 
after its initial activation. After liftoff, the plane had only reached an altitude of a few feetinstead of climbing the aircraft entered an aerodynamic stall a few seconds after rotation. In the course of a few seconds a normal flight appeared to have careened into the bay for no obviously apparent reason.

The factors leading up to this accident began long before the takeoff itself. The first leg of the flight was completed earlier that night by the same crew, with the First Officer completing an instrument approach to minimums without facing delays in the air. On the ground however the aircraft faced taxi congestion at LaGuardia, bringing them to the gate an hour behind schedule. After a pause to board passengers and prepare for the next leg of the flight, the aircraft was deiced with a fifty-fifty mixture of glycol and water known as Type I deicer. One of the ground service trucks caused a twenty-minute delay when, in the icy conditions, became stuck behind the aircraft blocking the path for a pushback. After it was moved the captain again requested that the airplane again be deiced a second time due to the commotion. Following their second deicing, however, the crew faced more delays as the snow was still congesting taxi operations. Altogether twenty-nine minutes had passed from the time of the last deicing procedure to the time the crew received takeoff clearance. The aircraft was now two hours behind schedule. During the taxi out, the First Officer (the only survivor from the flight crew) stated that he checked the wings, including a black "ice indicator strip", between three and ten times. Looking through the closed cockpit window from the right seat before takeoff, the wing seemingly appeared clear of ice. (NTSB, 1993)

Between the de-ice and the delayed taxi, the aircraft's previously clean wing had become substantially contaminated with snow and ice, reducing aerodynamic efficiency of the wingand the flight crew had few ways to tell, since the ability to see contamination on the wing from the closed cockpit window was extremely compromised from the right seat. During the investigation, the National Transportation Safety Board (NTSB) conducted a viewing test from an F-28 and found;

About 60 percent of the wing was visible when it was observed through both the sliding window and the window behind it.... It was difficult to see any details of any parts of the wing, such as rivets... When attempts were made to observe the black strip, it could only be seen through the scratched window behind the sliding window... the flat black strip was visible but distorted by the window glass. (NTSB, 1993, p. 40).

However, to the First Officer's knowledge there was no reason to doubt the veracity of the indicator in detecting contamination. Contrasting with the very negative outlook of the viewing test, the investigation report states that "throughout the investigation of this accident... [Fokker pilots] universally believed that they could detect any significant contamination from the cockpit". This suggests that flight crews of the Fokker never received company guidance stating anything to the contrary, when in fact tactile inspections of the wing were sometimes necessary to ensure a clean aircraft. (NTSB, 1993) This distinction between company accepted practice versus actual safe operation is an important topic that is touched on later in this paper.

Adding to the issue of the contaminated wing, one minor mistake was made by the crew by calling for $V_{R}$ five knots earlier than was calculated. This may have been due to the fact that 
they were using a reduced V1 speed ${ }^{5}$ — with most takeoffs in dry conditions, V1 and $V_{R}$ would have been stated at the same time. Due to the early rotation, drag was even more significant and wing angle of attack was increased above normal takeoff angle. It was found that the early rotation condition in conjunction with the uneven, rough ice accumulation caused the initial left wing drop as the aircraft stalled.

Characteristics of the Fokker F28 led it to be a particularly poor performer in icing conditions. Upon rotation, standard angle of attack for the Fokker was nine degrees. However even with very light icing contaminations of the upper wing, it was found that a nine-degree angle of attack would cause an aerodynamic stall as well as reduce lift by $33 \%$ or more. Other aircraft have comparably larger margins for standard vs. stalling takeoff angles of attack. Yet another factor leading to the poor icing performance was related to the position of the fuel tanks in the Fokker. Aircraft that were cold soaked, typically those returning from another leg such as USAir 405, would have extremely cold fuel due to the temperatures encountered at altitude. The fuel had the capability of cooling the wing surface to even lower temperatures than ambient.

During the investigation of the accident, it was found that $757 \mathrm{~s}$ which were deiced and held-over for a similar amount of time had no issues departing due to their leading edge slats ${ }^{6}$ and significant excess thrust. In fact, the aircraft that departed directly in front of USAir 405 was a 757 (NTSB, 1993). The lack of problems these aircraft had during their takeoff could have led to a false sense of security in the ability of the F-28 that night. The NTSB (1993) noted that the Federal Aviation Administration (FAA) had concerns about placing focus on those aircraft without leading edge devices in regard to icing, since the administration was under the impression that this would lead to carelessness on the part of pilots who flew aircraft with leading edge devices in icing.

At that point in time the crew had done everything that was expected of them by standard operating procedure to fully inform themselves as the state of the aircraft contamination. (Dismukes, Berman, \& Loukopoulos, 2007) The crew at the time of the accident was well qualified and had no record of incidents or deficiencies in training. The NTSB report of the accident states that "USAir flight crews received materials and training concerning winter operations consistent with, and in some cases, exceeding industry standards. The initial F-28 ground school emphasized the critical nature of the F-28 hard wing ${ }^{7} \ldots$. . While taxiing, the crew commented on poor nature of deicing being done at the gate rather than the runway, with conversation recorded on the CVR commenting on the new Denver airport's deicer pads:

"[Captain:] That's the ideal way of doing it man. . . They ought to have something like that- this is New York you know... they ought to have that out here."

"[First Officer:] That's really the only sure fire safe way to do it" (NTSB, 1993, p. 91)

Overall, there is a bigger picture insinuating that the Captain and First Officer were a knowledgeable crew that knew only some of the risk of icing takeoffs, and to the best of their

\footnotetext{
${ }^{5} V_{1}$ is the point at which the aircraft must continue the takeoff since there is not enough runway left to stop).

${ }^{6}$ Leading edge slats are devices which allow the aircraft to more easily fly at slow airspeeds.

${ }^{7}$ Hard wing refers to wings that lack a leading edge device, which allows the aircraft to generate lift at slow airspeed.
} 
knowledge, were free of ice contamination. Working contrary to them were the procedures and systems in place for the deicings themselves. The systems did not fully identify and account for all of the specific safety risks involved. According to the NTSB, USAir used the earlier Type I deicing fluid rather than the newer (at the time) Type II fluid. However, as stated earlier the board believed that the "procedures met or exceeded airline standards and were consistent with most of the industry". A problem revealed here is self-evident: even though all guidance from the FAA stated that the deicing was sufficient, the aircraft still took off with ice.

\section{Primary Concerns}

Procedures to identify, mitigate and continuously identify risk have undergone major changes in recent years through the mandatory development of Safety Management Systems (SMS). One especially important task of the SMS is the proper dissemination of risk information. Two instances in this accident stand out regarding poor dissemination of information. The first is the lack of reliability of the black ice indicator strip. The second is the ignorance of ground personnel that the Fokker may require a tactile inspection to confirm that the wing is clean of contamination.

Risk Dissemination is a critical component of a functional Safety Management System. Transport Canada, the Canadian equivalent of the FAA, has implemented a process flow which includes information dissemination as the final step of their SMS. Information dissemination according their policy includes trend analysis, safety bulletins, accidents, and report distribution (Stolzer, 2011). In 2013, Annex 19 to the Convention on International Civil Aviation was adopted into the Articles of the International Civil Aviation Organization (ICAO) and thus formally mandated the FAA and all member states to adopt SMS as the standard for airlines and the aviation industry (International Civil Aviation Organization, 2013). The system essentially allows for an organized process of risk assessment which in theory allows the user to predict risks as they emerge and compensate for them.

Accidents precursory to USAir 405 contained similarities that provided lessons to the FAA regarding icing. The NTSB (1993) accident report specifically makes mention of two important facts. "The investigation of past accidents has disclosed the difficulty involved with flight crews determining whether wings are clean. The industry acknowledges that it is nearly impossible to determine by observation whether a wing is wet or has a thin film ice". A disturbing aspect of the inference of this quote is that the necessity of up close inspection was well known to the industry as well as the FAA, while simultaneously remaining unknown to both ground personnel as well as flight crew at USAir. These critical portions of the company remained unaware of this risk due to the lack of dissemination of information. Ultimately, icing takeoffs were most likely very common in the era before this and other large scale icing accidents such as Air Florida Flight 90 in 1980 (Dismukes, et al, 2007).

Further supporting the idea that understanding of the risks associated with icing was inconsistent at USAir, some crews were found to be using their own improvised technique when they suspected contamination to be present. A captain for an airline which was later merged with USAir wrote a memo regarding icing takeoffs: "when wing contamination is suspected despite earlier preventative measures, rotation rates must not be excessive and takeoff speeds may be increased up to 10 knots. . . field length must be accounted for in the decision to rotate slower than $3^{\circ}$ per second. .." (NTSB 1993, p. 58). Fokker did not have a published procedure 
including this technique, nor was this technique published in the USAir Standard Operating Procedures. The disconnect between the informal procedure of USAir pilots and the standard operating procedure is one where the risk of icing takeoffs seems to be well understood by pilots yet not published under company approved procedures. The fact that this unwritten procedure was written but not used, or apparently known of, by the crew of USAir 405 suggests that this information was not disseminated successfully by the company. This is supported especially by the fact that the crew rotated five knots early, and rotated at an aggressive rate. This put them 15 knots slower than the guidance of the published memo.

The second procedural blunder came with respect to the use of the Captain's manually reduced V1 speed. Recent aviation incidents had been brought to the Captain's attention regarding the hazards of aborting a takeoff on a snowy runway. He decided that to reduce this risk they would establish a lower V1 speed. While this action was well intentioned with a conservative safety viewpoint in mind, it was improperly briefed and not part of standard operating procedure. The sense of timing in the crew's minds was thrown off and led to the early rotation (Dismukes et al., 2007).

These two examples of non-published procedures being used could be considered to fall under the category of normalization of deviance. Vaughan's (2009) book discusses normalization of deviance in the context of an extremely notable aviation disaster, the Challenger launch. She describes the endemic of normalization of deviance inside the National Aeronautics and Space Administration at the time as an effect of culture that resulted not from an attitude of rule breaking, but rather one of conformity. Likewise, as the crew of the Fokker prepared for takeoff that night they were not interested in breaking any rules. Rather, they were continuing with an unspoken tradition of taking off with questionable icing contamination. Had they used the unwritten procedure that the earlier memo stated, they would nonetheless still be following an unapproved procedure. Whereas the Challenger shuttle disaster is an example of normalization of deviance occurring as a side effect of external pressures and organizational culture, I argue that USAir 405 occurred in an organization where deviance was used to "fill in the gaps" of Standard Operating Procedure.

\section{Contemporary Examples}

Using the National Aeronautics and Space Administration's (NASA) Aviation Safety Reporting System (ASRS) ${ }^{8}$ (NASA 2016), we can find a broader picture of contemporary safety incidents caused by poor information dissemination that are still going on today. The function of ASRS finds its value through identifying repetitive trends in incidents, like many found previous to US 405 (the NTSB [1993] had listed several safety recommendations regarding icing that were not found acceptably fixed by the FAA).

In many of these instances where safety information is not properly disseminated, good airmanship and flight crews become the last line of defense 9 . Thankfully, due to the lessons

\footnotetext{
8 "The ASRS collects, analyzes, and responds to voluntarily submitted aviation safety incident reports in order to lessen the likelihood of aviation accidents." (NASA N.d.)

9 Airmanship, according to Ebbage \& Spencer (2004), is defined as "effective decision making to support a sequence of actions"
} 
learned from USAir 405 and the near universal abundance of deicing pads and maximum holdover times, the prevalence of takeoff icing contamination incidents in scheduled air carrier operations is remote. This accident, however, can be looked at in a big picture sense. I have selected five specific incidents from the ASRS to highlight those that seem to share the same underlying organizational cause of the USAir 405 accident.

We can take for instance this NASA ASRS report regarding a Boeing 777 crew's communications with weight and balance dispatchers. The crew had made an unscheduled stop at an intermediate airport during an intercontinental flight due to a crew rest time issue. During the stop, no passengers were deplaned except for a few flight attendants and bags, and the plane was restocked with food. The company dispatch report, however, gave them takeoff numbers and speeds which corresponded to aircraft performance at a weight which was twenty thousand pounds lighter. The dispatcher was queried and responded that it was a mistake that they were working on. Nevertheless, the dispatch sent back new weights which were now nine thousand pounds in excess of their weight when the aircraft arrived. The captain noticed the mistake again before finally receiving corrected weights.

While this is an exemplary instance of a flight crew overcoming poor information that is being presented to them, there is a disconnect here regarding the dispatcher's versus the Captain and First Officer's assessments of risk. The Captain stated, "[h]ad we not queried the load planner with the original 19,670-pound decrease, which was not correct, and used that data for takeoff and experienced an abort at V-1, we would have gone off the end of the runway and killed everyone on board!'. Later, the Captain says that the attitude of the dispatcher on Satellite phone was "indignant" (National Aeronautics and Space Administration [NASA], 2016, No. 1379224). Barring a willfully negligent employee, it seems that the dispatcher may have not fully understood the implications of an improper V1 speed. Judging by this incident, the crosscheck of the flight crew in calculating the performance numbers was vital. This incident supports the argument that safety information must be disseminated among all levels of the company, not just flight crews. In this case, the flight crew luckily caught the mistakes of the dispatchers but faced serious communication issues.

Another example where a communication breakdown was a contributing factor occurred somewhere over the airspace of Southern California Approach. A "super heavy" weight-class Airbus A380 took off with an approximate weight of 1.2 million pounds. In a clean configuration the aircraft had a minimum safe maneuvering speed of two hundred eighty knots. Upon advising the controller that they were required to exceed two hundred fifty knots, he scolded them, accusing the crew of "playing games". According to the pilot, "A less fortunate and less trained crew very well might have had a clean aircraft too slow (250 knots, as the controller mandated) and caused a serious safety concern" (NASA, 2016, No. 1376325). The speed regulation, what the controller seemed to think was a non-waiverable requirement of airspeed, led to pressure on the flight crew to do something unsafe. It is unlikely that there was company guidance on reacting to controller pressure to do something the aircraft isn't safely capable of doing.

A commonality between this situation and the situation at USAir in the years preceding the accident of 405 is the inconsistency of understanding within the scope of procedures. The "unwritten procedure" for icing takeoffs was one that many USAir pilots understood as necessary but was simultaneously unpublished by Fokker. In addition, the crew of 405 was 
under the impression that the black icing strip was an acceptable form of checking for wing contamination. Other pilots may have known that it was a vastly ineffective way of determining contamination. The commonality between the two situations is a disconnect in understanding between involved parties. The pilots knew that an A380 near maximum gross weight could not safely perform at the prescribed airspeed. The controller did not. The controller may not have even been aware that the requirement to fly faster than 250 knots is waivable for those aircraft that require it (Aircraft Speed, 1993). Modern Crew Resource Management relies on the collaboration between those not only in the company, but also air traffic controllers and any others involved in the flight (Kanki, Helmreich \& Anca, 2010). Like the previous contemporary incident regarding the weight dispatchers, two of the agents involved were understanding present risk in two different ways. Thusly the risk in this situation sprouted from a lack of shared and disseminated risk information.

Notably, one study done of 28,000 ASRS reports found that $70 \%$ of all reports fell into the category of communication issues: "the most common findings showed that information was not transferred because (1) the person who had the information did not think it necessary to transfer it or (2) that the information was transferred, but inaccurately." (Billings \& Cheney, 1981, p. 2) Reason (1) is extremely relevant to the scope of this paper. A lack of transfer due to the controller thinking the information is not important is, itself, an incorrect risk analysis that caused information not to be disseminated.

Techniques have been introduced by industry experts to increase the awareness of unidentified hazards in aviation operations. At the proceedings of The International Congress on Aeronautical Sciences (N.d.), a method was devised where a group of experts are brought together for brainstorming with a moderator present (who is themselves a safety expert), after which the group decides by individual vote which hazards should be looked into. The idea is that a company could cut down on any unimagined risk through brainstorming. Techniques such as these could prove valuable to an organization in proactively finding faults in any system devised. Similar programs have taken hold at air carriers through using a Safety Management System, which as discussed earlier, has become industry standard. These systems use a circular flow to mitigating risk. Step one is straightforward: find the risk. In the case of flight 405, while contamination risk was documented by previous Advisory circulars and FAA regulations, the crew was not sufficiently up-to-date on understanding of it. This was due to a failure of step two and beyond in the safety management flow: analysis and implementation.

An emerging realm of aviation presents new challenges regarding risk dissemination. Part 107 of 14 Code of Federal Regulations (CFR) provides for the commercial use of drones and takes the place of what was previously called the Section 333 exemption in the 14 CFR. Drone pilots, under the regulation, must at a minimum undergo online training but are not required to be manned aircraft pilots (Small Unmanned Aircraft Systems, 2016). This introduces the issue of drone pilots lacking aviation knowledge that can be passed on through a flight instructor as manned pilots have. One particular ASRS report mentions a near miss by a drone pilot. The drone pilot is thorough in his or her planning but nonetheless encounters another aircraft:

I was operating a drone under Part 107 collecting aerial photographs. . . I had filed a UAS operating area report with Flight Services in an effort to warn air traffic ... [including] the altitude I would be at, and the exact times of operation. We also had a hand held [radio] turned on and operating. . . A visual observer was also on site and fully briefed. . The visual observer yelled out an aircraft 
sighting . . . and [I] saw a Cessna 172 flying at approximately the same altitude as the drone on what appeared to be a collision course approximately .4-.25 miles from the drones position. The Cessna pilot did not seem to see the drone, he was operating at or below $500 \mathrm{ft}$ in my estimation, and was obscured from view ... There needs to be a better way to freely communicate drone activities with pilots and more emphasis given to pilots to check UAS operating areas before they fly, especially when flying below or near 400 ft AGL. (NASA, 2016, No. 1410141)

In this case, a unique threat occurs in that see-and-avoid techniques become more difficult from both the drone pilot's as well as the manned pilot's perspective. For the manned pilot, consumer drones used for videography often weigh only a few pounds and measure approximately one foot across, making it significantly more difficult to spot. For the drone pilot, there is a comparably much lower line of sight that she or he is able to view traffic through. While the drone operator here did their due diligence on the ground, the manned pilot apparently did not know of the UAS operating area which was, in contrast, well known to flight service. Had the Cessna pilot known about the drone operations, the pilot would have been able to use other services such as contacting the drone operator on the aviation radio to maintain awareness of its position. Meanwhile the drone operator did not know of low level flying occurring in the area. This all suggests that there are new opportunities for researching information sharing regarding the interaction of drones and manned aircraft. More broadly it harkens to the original accident analyzed due to the confusion on parts of both operators. The near-miss highlights the disconnect between Flight Service, the operator on the ground, and the pilots in the air.

Operations manuals, both company and aircraft, played a critical point of investigation for the NTSB regarding USAir 405. In this next incident analysis, one airline pilot submitted an ASRS report alerting the company about a section in the aircraft operating manual regarding freezing rain:

For the record, I have NEVER seen more conflicting confusion information on a topic of such importance. It needs to be clear and concise. Easy to follow along and easier to understand. The entire winter ops ...ice ...cold weather section is NOT any of this.

Also, and probably more importantly, every time something is updated in any of our manuals on the iPad, you basically have NO idea what was changed/modified/deleted. It is now impossible to keep track of important safety of flight information. In the "old days" we could make and keep notes in the margin and review changes. (NASA, No. 1407973)

This report is eerily similar in many ways to what was found in the aftermath of 405 . While the author of this report does not specifically mention what was missing in the manual regarding freezing rain, he or she implies that it was critical to the safety of flight. The pilot later mentions even asking a dispatcher friend of theirs if they have heard of the specific aircraft restriction in that type of weather, and he or she replied that they did not. The company's solution was to add a note onto dispatch releases in certain weather which clarified the information. As noted by the pilot, the iPad (or more generally, electronic flight bags [EFBs]) introduces benefits, but also new risks. The technology could have the ability to disseminate 
risk information and assessment more easily to entire companies, but in this pilot's judgement it was not doing so properly. This is acknowledged in the conclusions of Billings and Cheney (1981) regarding dissemination of information. As technological solutions are introduced, they state, it "may give rise to serious new problems unless they are implemented with an understanding of the capabilities and limitations of the humans who operate [them]" (p. 13).

Following this trend, a notable incident report occurred when a CRJ-200 ${ }^{10}$ pilot, after arriving at the destination, noticed ground handlers unloading ballast bricks from the cargo hold. The pilot however did not notice said ballast listed on the weight and balance dispatch form before the flight. Upon conversing with ground supervisors, it was confirmed that these were not accounted for before departure. The captain summarily noted, "anyone involved in ANY part of the loading process should have a box to sign or initial on the Cargo Load Report AFTER reviewing it and ensuring that ALL information is correct." (NASA, No. 1379603) A consistency in this report as it relates to both USAir 405 and the previous reports is that there is a breakdown in the line of communication between crew and others. Interestingly, a technology introduced to attempt to fix the solution may have caused another problem. "The scanners used by ramp personnel seem to be very useful for maintaining an accurate bag count. However, there is no way to scan a brick of ballast as it ascends the belt loader. Ramp crew must rely on their fingers and toes to keep an accurate count. Perhaps a generic bar code could be added to each ballast brick so that it may be scanned and counted electronically before being transferred to the Cargo Load Report." It might be that as the ramp crew were typically relying on the automated bag scanner, complacency was introduced for other, non-typical items such as ballast.

\section{Conclusion}

As shown, NASA ASRS reports have proven incredibly useful in studying risks in aviation since they are focused on the actual day to day operations of pilots. Systems such as these should continue to be utilized and refined, and combined with systems that can analyze them effectively to prevent future problems or incidents. A notable limitation of ASRS reports is that they are not able to be directly linked to audio recordings (or if they are, that aspect is not analyzed by NASA themselves). Analysis of actual audio files or transcripts could be valuable in studying this type of communications error due to the reports themselves being biased by reporter viewpoints (Kanki et al., 2010). However, dissemination of information through controller interactions is only one of the issues mentioned in this paper. In a wider scope, SMS utilized by companies should include analyses to ensure that "hypothetical" company operations (i.e. the recommendations and guidance published in manuals) is in line with how companies operate in reality (e.g. during line flights and the everyday work of employees). Typically, normalization of deviance is characterized as the habit of a maverick that is uninterested in safety. USAir and its safety-minded crew showed otherwise. Normalization of deviance rather seems to occur particularly when company policy is lacking in some manner.

Before implementation, I recommend that policies be scrutinized by companies and put into testing and feedback processes. Since the implementation of holdover times and deicing pads, the accident of USAir 405, which took twenty-seven lives, has not been in vain. This was

${ }^{10}$ The CRJ200 (Canadair Regional Jet) is a twin-engine regional jet capable of carrying 40-50 passengers. 
unfortunately due mainly to a retroactive effort. Aviation accidents have the ability to highlight the lacking aspects of aviation safety, but they do not have to occur before issues are solved. 


\section{References}

Aircraft Speed, 14 C.F.R. \91 (1993).

Billings, C.E., Cheaney, E.S., 1981. Information Transfer Problems in the Aviation System (NASA Technical Paper 1875). NASA Ames Research Center, Moffett Field, CA.

Dismukes, K., Berman, B. A., \& Loukopoulos, L. D. (2007). The Limits of Expertise : Rethinking Pilot Error and the Causes of Airline Accidents. Aldershot: Ashgate.

Ebbage, L. \& Spencer, P.D. (2004). Airmanship Training For Modern Aircrew. Proceedings from RTO Human Factors and Medicine Panel (HFM) Symposium. Genoa, Italy. doi:10.14339/RTO-MP-HFM-101

International Civil Aviation Organization. (2013). Annex 19 to the Convention on International Civil Aviation. Montreal, Quebec

Kanki, B. G., Helmreich, R. L., \& Anca, J. M. (2010). Crew resource management. Amsterdam Boston : Academic Press/Elsevier, c2010.

Kleinfield, N.R. (1992 March 29). The Ordinary Turned to Instant Horror for All Aboard USAir's Flight 405. The New York Times.

National Aeronautics and Space Administration (N.d.) Aviation Safety Reporting ProgramProgram Briefing. Retrieved from https://asrs.arc.nasa.gov/overview/summary.html

National Aeronautics and Space Administration. (2016). ASRS Database Online. Retrieved from http://asrs.arc.nasa.gov/

(NASA ASRS Accession No. 1379224)

(NASA ASRS Accession No. 1376325)

(NASA ASRS Accession No. 1410141)

(NASA ASRS Accession No. 1407973)

(NASA ASRS Accession No. 1379603)

Smith, Brian E., Hans H. De Jong, Mariken H.C. Everdij, \& NASA Ames Research Center. (2008) A Prognostic Method to Identify Hazards for Future Aviation Concepts.. 26th International Congress of Aeronautical Sciences. Retrieved from http://www.icas.org/ICAS_ARCHIVE/ ICAS2008/PAPERS/634.PDF

Small Unmanned Aircraft Systems, 14 C.F.R. \$107.53-107.79 (2016).

Stolzer, A. J., Goglia, J. J., \& Halford, C. D. (2011). Implementing Safety Management Systems in Aviation. Surrey, England: Routledge. 
United States of America. National Transportation Safety Board. NTSB/AAR-93/02. Springfield, VA: National Technical Information Service, 1993.

Vaughan, D. (1997). The Challenger launch decision: Risky technology, culture, and deviance at NASA. University of Chicago Press. 